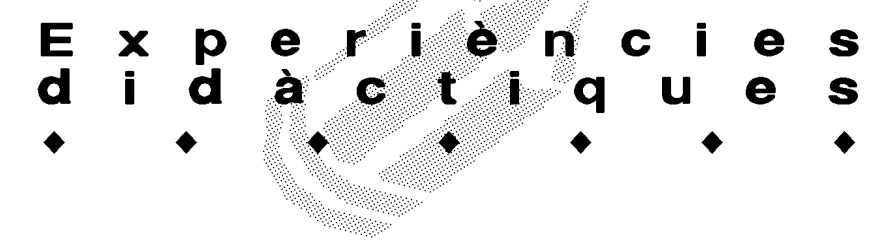

\title{
LA CREACIÓ D'UNA CORAL A L'ESCOLA: UN REPTE PER ALS ESPECIALISTES D'EDUCACIÓ MUSICAL
}

\author{
Montserrat Ríos Hevia. Àrea de Música. URV
}

Dins de l'escola, cada grup classe forma, per ell mateix, una "coral infantil", però de ben segur que hi ha molts nens $i$ nenes a qui agrada molt més cantar que a d'altres i que segurament voldrien participar, (després d'una possible selecció de l'especialista) en una coral molt especial, que representi el centre en qualsevol tipus d'activitat musical: trobades, festes, intercanvis amb altres corals infantils... També pot col-laborar amb altres grups artístics de la mateixa escola o del barri o poble on aquesta estigui ubicada: grups de teatre, dansa clàssica o tradicional, activitats plàstiques, etc.

Aquesta activitat serà enriquidora tant per als nens que hi participen com per a tota la comunitat escolar, i permetrà el desenvolupament de la comunicació entre les persones mitjançant un dels instruments més ancestrals que pertany a la cultura de tots els pobles del món: el cant coral.

\section{Alguns aspectes materials $i$ tècnics}

Hi ha una sèrie de característiques que hem de tenir en compte a l'hora de posar-nos a treballar.

- La sala d'assaig ha de ser espaiosa i amb una acústica que permeti que els nens s'escoltin correctament entre ells, i també al mestre-director realitzar la seva feina sense dificultats. Ha de tenir finestres per poder oxigenar-la quan sigui necessari, i permetre una bona il-luminació.

- Les cadires han de ser apropiades a l'alçada dels nens; hem de procurar que no tinguin els peus penjant i que l'esquena estigui recta.

- Pel que fa a la utilització d'instruments (piano, guitarra...) durant l'assaig, intentarem fer-ne un ús limitat a les obres que ho requereixin. És molt millor treballar sense instruments tot el repertori "a capella".

\section{Preparació de l'assaig}

Qué podem fer a casa per preparar l'assaig?

Per poder fer cantar una obra musical, sigui o no molt complicada, el primer que es requereix és, evidentment, el seu estudi aprofundit; però, per preparar l'assaig, hi ha una sèrie d'elements que ens poden ajudar:

- Buscar les frases musicals, la periodicitat, els punts culminants, l'harmonia implícita.
- Anotar els compassos que presentin algun tipus de dificultat específica, ja sigui rítmica (síncopes, contratemps, tresets...), melòdica, vocal (entonació, tesitura), cromatismes, dissonàncies...

- Escriure el text i imaginar la situació en què es trobava el poeta quan el va escriure: Quins sentiments ha volgut expressar? Què vol dir amb aquestes paraules? Estava trist, cansat, feliç... És una persona jove, un nen, un avi el que parla? Potser es una música escrita per ser ballada?

\section{Referent a la pedagogia de l'assaig. El repertori}

- Intentarem que sigui variat i viu, alternant cançons d'estils i dinàmiques diferents.

- No deixarem mai gaire estona una part del grup sense cantar. Quan treballem cançons a una o més veus, és un bon sistema que tots ho aprenguin tot i així no tenim aquest perill.

- Tenir molta cura dels atacs de so quan comença la cançó, així com dels finals de frase (fer que el grup s'escolti constantment).

- Donar el touna sola vegada, quan els nens estiguin en silenci.

- Utilitzar el diapasó molt sovint per poder controlar l'afinació, i corregir, si és necessari, amb propostes didàctiques alternatives (no serveix de res la simple repetició d'una cosa per corregir-la).

- Cuidar les veus del grup i no cansar-les inútilment (sobretot en cas de la utilització de tesitures extremes).

- No oblidar que la nostra actitud i el nostre gest de direcció ha de "convidar" a cantar.

Un altre aspecte molt important és l'elecció dels repertoris. Els directors passem molt de temps buscant obres de qualitat que permetin millorar el nivell del grup i que alhora siguin un plaer interpretatiu per als nens i per al públic.

Pensem que el repertori escollit durant un curs farà que la nostra feina sigui més o menys profitosa, tant per a nosaltres com per als nens, i que d'això pot dependre que algun nen es cansi i no tingui ganes de tornar a la coral el proper curs. Hem de preveure que la majoria de dificultats que presenti l'obra es podran superar, i que els nens tindran el plaer i la satisfacció d'haver assolit els objectius que ens havíem proposat: cantar amb la veu i amb el cor les cançons que no oblidarem mai. 